\title{
Wnt3a expression is associated with poor prognosis of esophageal squamous cell carcinoma
}

\author{
JUNYA OGUMA $^{1}$, SOJI OZAWA ${ }^{1}$, AKIHITO KAZUNO ${ }^{1}$, MIHO NITTA ${ }^{1}$, \\ YAMATO NINOMIYA $^{1}$ and HIROSHI KAJIWARA ${ }^{2}$ \\ Departments of ${ }^{1}$ Gastroenterological Surgery and ${ }^{2}$ Pathology, Tokai University School of \\ Medicine, Isehara, Kanagawa 259-1193, Japan
}

Received June 28, 2017; Accepted November 7, 2017

DOI: $10.3892 / \mathrm{ol} .2017 .7666$

\begin{abstract}
The Wnt signaling pathway is widely implicated in various types of cancer. Canonical Wnt signaling, including Wnt3a, may be a key component of cancer progression or chemoresistance. Consequently, it was hypothesized that Wnt3a expression may be a prognostic factor of esophageal squamous cell carcinoma (ESCC) due to its roles in chemoresistance and tumor progression. The aim of the present study was to investigate the association between Wnt3a expression and prognosis in patients with ESCC. Wnt3a expression was evaluated in resected specimens from 139 patients with thoracic ESCC who were subjected to curative surgery without neoadjuvant therapy in Tokai University Hospital between 2007 and 2009. Samples were assessed using immnohistochemistry. Patients with ESCC were divided into two groups according to the expression of Wnt3a in tumor tissue. The influence of Wnt3a expression on clinicopathological findings and prognosis of ESCC were subsequently investigated. Immnohistologically, 68 cases were Wnt3a-positive in the cytoplasm of cancer cells, whereas 71 cases were negative. Multivariate analysis by Cox proportional hazard model showed the association between $\mathrm{pN}(\mathrm{HR}=3.539, \mathrm{P}=0.001)$, venous invasion $(\mathrm{HR}=2.798, \mathrm{P}=0.012)$, Wnt3a expression $(\mathrm{HR}=1.691, \mathrm{P}=0.046)$ and overall survival (OS). OS rate and disease-free survival rate were poorer in Wnt3a-positive group compared with those in the Wnt3a-negative group as indicated by the log-rank test $(\mathrm{P}=0.012$ and $\mathrm{P}=0.023$, respectively). In pathological stages I and II, there was no significant difference in the OS rate between Wnt3a-positive and Wnt3a-negative groups; however, the OS rate of the Wnt3a-positive group was significantly worse than that of Wnt3a-negative group in pathological stage III (log rank test; $\mathrm{P}=0.017)$. Wnt3a-positive
\end{abstract}

Correspondence to: Professor Soji Ozawa, Department of Gastroenterological Surgery, Tokai University School of Medicine, 143 Shimokasuya, Isehara, Kanagawa 259-1193, Japan

E-mail: sozawa@tokai.ac.jp

Key words: esophageal squamous cell carcinoma, canonical Wnt signaling pathway, Wnt3a, prognostic factor, chemoresistance patients with recurrence had a significantly poorer prognosis compared with Wnt3a-negative patients (log-rank test; $\mathrm{P}=0.023)$. The present findings suggested that $\mathrm{Wnt} 3 \mathrm{a}$ may be a prognostic factor of ESCC.

\section{Introduction}

Esophageal squamous cell carcinoma (ESCC) has poor prognosis in comparison with other gastrointestinal cancer. Especially, prognosis of advanced or recurrent ESCC is extremely poor (1) and main standard treatment of it is chemotherapy. However, chemotherapy for esophageal cancer is not extremely effective and safe at the present time. Clinical useful biomarker of ESCC will be detected on the molecular biological experiments and then development of more effective and safe therapies are expected.

The Wnt signaling pathway is pivotal in embryogenesis and development and aberrant activation of canonical Wnt signaling is also widely implicated in a number of human disease such as cancer $(2,3)$. $\beta$-catenin, which is a central molecule in the canonical Wnt pathway, translocates from a free cytosolic form to the nucleus and then plays a role as a cofactor with T-cell factor/lymphoid enhancer factor in order to trigger gene transcription (4-6). Recently it was suggested that abnormal expression of some key components of canonical Wnt signaling pathway, such as $\beta$-catenin, GSK-3 $\beta$, Axin, APC and some ligands of this pathway, was associated with the development and progression of gastroenterological cancer such as colon cancer $(7,8)$, hepatocellular carcinoma $(9,10)$ and so on. There is also a study which suggested that Wnt 2 which was secreted by tumor fibroblast and activated the canonical Wnt signaling pathway leaded to poor prognosis of ESCC (11). Wnt3a is one of typical ligands of the canonical Wnt signaling pathway. It has been regarded as an activator of the canonical Wnt signaling pathway including nuclear accumulation of $\beta$-catenin. Several studies suggested that high expression of Wnt3a in many kinds of tumors was correlated with a worse clinical outcome $(12,13)$. Moreover, it was reported that Wnt3a regulated self-renewal of prostate cancer cells with stem cell characteristics (14). However, the clinical significance of Wnt3a expression in ESCC is not clear. We thought that canonical Wnt signaling, including Wnt3a, might be a key component of cancer progression or chemoresistance, and we hypothesized 
A

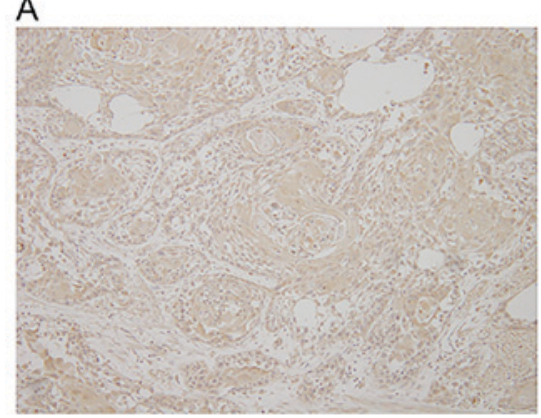

C

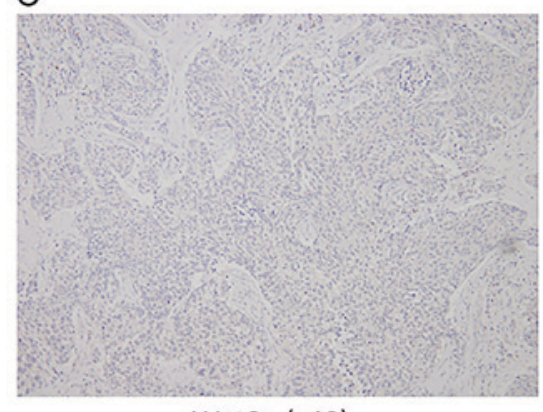

Wnt3a (x40)
B

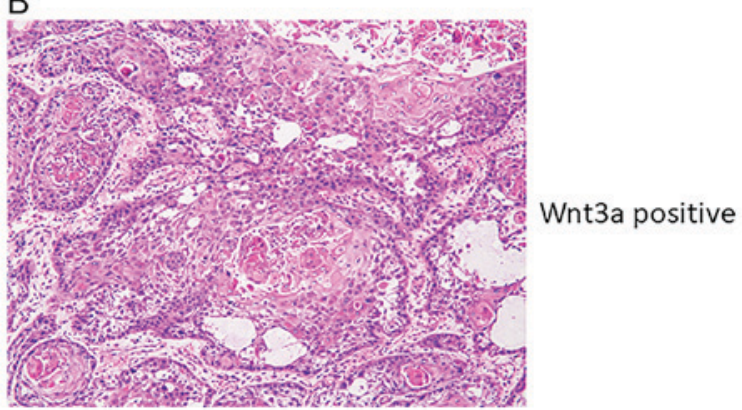

D

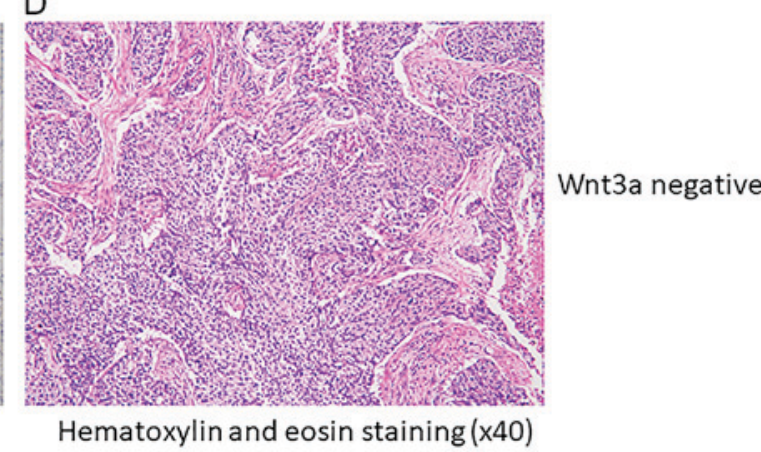

Figure 1. Wnt3a expression by immnohistochemical staining for resected specimen with ESCC. (A) Representative specimen with Wnt3a-positive ESCC. Cytoplasm was uniformly stained in ESCC tissue. (B) Hematoxylin and eosin (H\&E) staining in ESCC tissue same as A. (C) Representative specimen with Wnt3a-negative ESCC. Cancer cells were not applicable stained at the same as stroma cells. (D) H\&E staining in ESCC same as C.

that Wnt3a expression might be a prognostic factor of ESCC because of its roles in chemoresistance and tumor progression.

The aim of this study is to investigate the relationship between Wnt3a expression in ESCC tumor and prognosis in patients with ESCC.

\section{Materials and methods}

Patient selection. Wnt3a expression was evaluated in resected specimens from 139 patients with pathological stages I-III thoracic ESCC who underwent thoracic esophagectomy with three field lymphadenectomy without neoadjuvant therapy in Tokai University Hospital from 2007 to 2009. Staging was defined as following UICC TNM classification 7th edition. Adjuvant chemotherapy was performed for patients with pathological stage III ESCC in principle, however elder patients, patients with renal dysfunction or patients who rejected it did not perform it. Adjuvant chemotherapy consisted of a combination 5-fluorouracil (5-FU) and cisplatin, and $800 \mathrm{mg} / \mathrm{m}^{2}$ 5-FU was given by continuous intravenous infusion on day 1-5 and $80 \mathrm{mg} / \mathrm{m}^{2}$ cisplatin by intravenous infusion. This regimen consisted of two cycles of chemotherapy separated by a 3-week interval. The important clinicopathological information of each patient was collected from the medical records. The present study was approved by the Ethics Committee of Tokai University, School of Medicine (Kanagawa, Japan). The need for written informed consent was waived due to the retrospective, non-interventional nature of the present study.

Immnohistochemical staining. Resected specimens were fixed in $10 \%$ formaldehyde at $4^{\circ} \mathrm{C}$ for $10 \mathrm{~h}$. Paraffin block sections of ESCC were deparaffinised. For antigen retrieval, the sections were boiled at $120^{\circ} \mathrm{C}$ in citrate buffer ( $\mathrm{pH} \mathrm{6.0)}$ for $5 \mathrm{~min}$ and peroxidase was quenched with methanol and $3 \% \mathrm{H}_{2} \mathrm{O}_{2}$ at room temperature for $10 \mathrm{~min}$. These were blocked with $5 \%$ normal goat serum for $10 \mathrm{~min}$ and incubated with mouse anti-Wnt3a monoclonal antibody (dilution 1:50; Abcam, Cambridge, MA, USA) overnight at $4^{\circ} \mathrm{C}$. Additionally, these sections were incubated with peroxidase-labeled anti-rabbit antibody (Histofine Simple Stain Max PO; Nichirei, Tokyo, Japan) for $30 \mathrm{~min}$ at room temperature. For the negative control reaction, phosphate-buffered saline was used instead of the primary antibody.

Positive expression of Wnt3a was detected when brown granules were identified in the cytoplasm and more than $10 \%$ of the cancer cells in each sections were immunoreactive to Wnt3a (15). Non-cancerous tissues in the resected specimens were used as a negative control. The results of immnohistochemical staining were assigned by two independent investigators without knowledge of clinicopathological data. One hundred thirty nine patients with ESCC were divided to two groups according to expression of Wnt3a in tumor tissue. Two groups were compared about clinicopathological findings and prognosis, and we investigated the influence of Wnt3a expression on ESCC.

Statistical analysis. Statistical analysis was performed using SPSS software (version 24; SPSS Inc., Chicago, IL, USA). The difference of clinicopathological findings between Wnt3a-positive and Wnt3a-negative groups was analyzed by Chi-square test and Student's t-test. Cox's proportional hazard regression model was used to analyze the independent prognostic factors with univariate and multivariate analysis. Survival rates was calculated using Kaplan-Meier method and these of two groups were compared by the log rank test. $\mathrm{P}<0.05$ was considered to indicate a statistically significant difference. 
Table I. Comparison of clinicopathological factors between Wnt3a-positive and Wnt3a-negative groups. A Chi-square test was performed comparing all subgroups in each factor.

\begin{tabular}{|c|c|c|c|c|}
\hline Parameters & Total $(n=139)$ & Wnt3a-positive (n=68) & Wnt3a-negative (n=71) & P-value \\
\hline Age (years; mean) & 64.3 & 65.4 & 63.3 & 0.741 \\
\hline Sex & & & & 0.907 \\
\hline Male & 115 & 56 & 59 & \\
\hline Female & 24 & 12 & 12 & \\
\hline Location of tumor & & & & 0.435 \\
\hline Upper & 19 & 9 & 10 & \\
\hline Middle & 78 & 35 & 43 & \\
\hline Lower & 42 & 24 & 18 & \\
\hline Size of tumor (mm; mean) & 52.8 & 53.2 & 52.4 & 0.163 \\
\hline Serum SCC level (ng/ml; mean) & & & & 0.834 \\
\hline$\geq 1.5$ & 28 & 13 & 15 & \\
\hline$<1.5$ & 111 & 55 & 56 & \\
\hline Differentiation & & & & 0.028 \\
\hline Well & 43 & 19 & 24 & \\
\hline Moderate & 63 & 27 & 36 & \\
\hline Poorly & 33 & 22 & 11 & \\
\hline Lymphatic invasion & & & & 0.780 \\
\hline Positive & 109 & 54 & 55 & \\
\hline Negative & 30 & 14 & 16 & \\
\hline Venous invasion & & & & 0.172 \\
\hline Positive & 101 & 53 & 48 & \\
\hline Negative & 38 & 15 & 23 & \\
\hline INF & & & & 0.240 \\
\hline $\mathrm{a}$ & 5 & 4 & 1 & \\
\hline $\mathrm{b}$ & 111 & 51 & 60 & \\
\hline $\mathrm{c}$ & 23 & 13 & 10 & \\
\hline pT & & & & 0.019 \\
\hline 1 & 60 & 23 & 37 & \\
\hline 2 & 22 & 9 & 13 & \\
\hline 3 & 57 & 36 & 21 & \\
\hline $\mathrm{pN}$ & & & & 0.475 \\
\hline 0 & 47 & 21 & 26 & \\
\hline 1 & 92 & 47 & 45 & \\
\hline pStage & & & & 0.322 \\
\hline I & 32 & 12 & 20 & \\
\hline II & 50 & 24 & 26 & \\
\hline III & 57 & 32 & 25 & \\
\hline Adjuvant chemotherapy & & & & 0.607 \\
\hline+ & 80 & 41 & 39 & \\
\hline - & 59 & 27 & 32 & \\
\hline
\end{tabular}

SCC, squamous cell carcinoma; INF, infiltrative growth pattern; pT, pathological T; pN, pathological N; pStage, pathological stage.

\section{Results}

Immnohistologically, 68 cases (49\%) were Wnt3a-positive in cytoplasm of cancer cells (Wnt3a-positive group), and 71 cases (51\%) were negative (Wnt3a-negative group) (Fig. 1).
Background data of clinicophathological features in both group was shown in Table I. There was no significant difference between two groups in age, sex, location of tumor and size of tumor. In Wnt3a-positive group, the number of patients with poor differentiated carcinoma $(\mathrm{P}=0.028)$ and $\mathrm{T} 2$ or deeper of 
Table II. Univariate and multivariate survival analysis of overall survival for ESCC patients by Cox's proportional hazard model.

\begin{tabular}{|c|c|c|c|c|c|c|}
\hline \multirow[b]{2}{*}{ Parameters } & \multicolumn{3}{|c|}{ Univariate analysis } & \multicolumn{3}{|c|}{ Multivariate analysis } \\
\hline & HR & $95 \% \mathrm{CI}$ & P-value & HR & $95 \% \mathrm{CI}$ & P-value \\
\hline \multicolumn{7}{|l|}{ Age (years) } \\
\hline$\geq 65$ vs. $\leq 64$ & 1.484 & $0.892-2.468$ & 0.128 & & & \\
\hline \multicolumn{7}{|l|}{ Sex } \\
\hline Male vs. female & 1.098 & $0.557-2.168$ & 0.787 & & & \\
\hline \multicolumn{7}{|l|}{ Location of tumor } \\
\hline Upper vs. middle and lower & 1.545 & $0.781-3.053$ & 0.211 & & & \\
\hline \multicolumn{7}{|l|}{ Size of tumor } \\
\hline$\geq 49$ vs. $\leq 48$ & 1.651 & $0.997-2.736$ & 0.051 & & & \\
\hline \multicolumn{7}{|l|}{ Serum SCC level } \\
\hline$\geq 1.5$ vs. $<1.5$ & 1.118 & $0.605-2.066$ & 0.723 & & & \\
\hline \multicolumn{7}{|l|}{ Adjuvant chemotherapy } \\
\hline Done vs. not done & 1.390 & $0.819-2.357$ & 0.222 & & & \\
\hline \multicolumn{7}{|l|}{ Differentiation } \\
\hline Poorly vs. well, moderate & 2.012 & $1.191-3.397$ & 0.009 & & & \\
\hline \multicolumn{7}{|l|}{ Infiltrative growth pattern } \\
\hline c vs. a, b & 1.357 & $0.721-2.556$ & 0.344 & & & \\
\hline \multicolumn{7}{|l|}{ Lymphatic invasion } \\
\hline Positive vs. negative & 3.126 & $1.252-7.808$ & 0.015 & & & \\
\hline \multicolumn{7}{|l|}{ Venous invasion } \\
\hline Positive vs. negative & 3.424 & $1.557-7.532$ & 0.002 & 2.798 & $1.259-6.215$ & 0.012 \\
\hline \multicolumn{7}{|l|}{ pT } \\
\hline 3 vs. 1,2 & 2.534 & $1.446-4.442$ & 0.001 & & & \\
\hline \multicolumn{7}{|l|}{$\mathrm{pN}$} \\
\hline 1 vs. 0 & 3.833 & $1.884-7.798$ & $<0.001$ & 3.539 & $1.728-7.248$ & 0.001 \\
\hline \multicolumn{7}{|l|}{ Wnt3a expression } \\
\hline Positive vs. negative & 1.906 & $1.141-3.185$ & 0.014 & 1.691 & $1.009-2.836$ & 0.046 \\
\hline
\end{tabular}

Infiltrative growth pattern: a, expansive type; b, intermediate type; and c, infiltrative type. HR, hazard ratio; ESCC, esophageal squamous cell carcinoma; CI, confidence interval; pT, pathological T; pN, pathological N.

pT $(\mathrm{P}=0.019)$ than these in negative group. There was no significant correlation between lympatic invasion, venous invasion, $\mathrm{pN}$, pStage and Wnt3a expression. There was not significant difference of recurrent rate between two groups. There was not also difference of recurrent patterns, however frequency of recurrence at distant organs in Wnt3a-positive group tended to be higher than that in negative group $(\mathrm{P}=0.051)$ Median follow-up period of Wnt3a-positive group was 37 months and that of Wnt3a-negative group was 44 months, and there was no difference between two groups $(\mathrm{P}=0.172)$. Multivariate analysis by Cox proportional hazard model showed the relationship between $\mathrm{pN}(\mathrm{HR}=3.539, \mathrm{P}=0.001)$, venous invasion $(\mathrm{HR}=2.798$, $\mathrm{P}=0.012)$, Wnt3a expression $(\mathrm{HR}=1.691, \mathrm{P}=0.046)$ and overall survival (OS) (Table II), and the relationship between only $\mathrm{pN}$ $(\mathrm{HR}=1.658, \mathrm{P}<0.001)$ and disease free survival (DFS). These parameters were identified as independent prognostic factors for ESCC. On the other hand, serum SCC antigen level, which was a former indicator of progression of ESCC as one of typical tumor marker, was not related to prognosis.

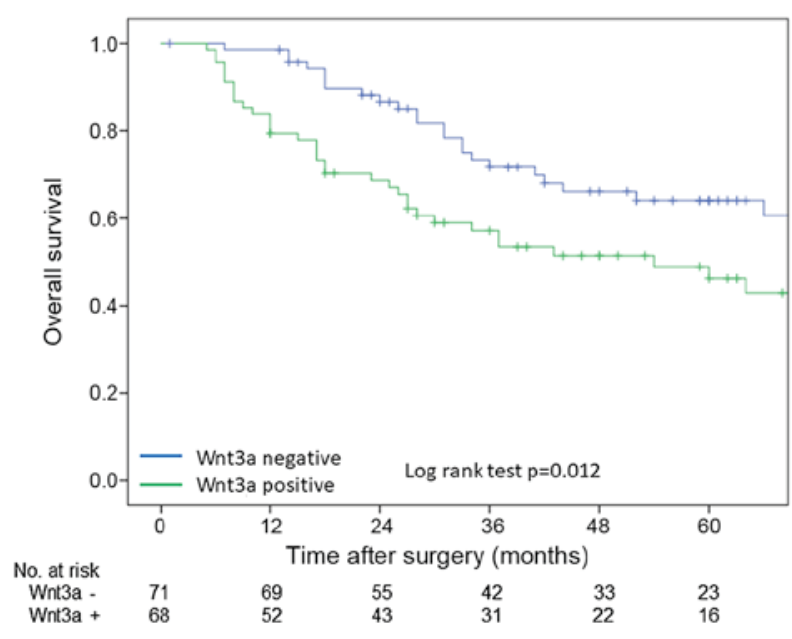

Figure 2. OS curves of all patients according to Wnt3a expression. These curves were calculated by the Kaplan-Meier method. The green line is Wnt3a-positive group and the blue line is Wnt3a-negative group. Difference between two groups were evaluated by log-rank test. OS, overall survival. 


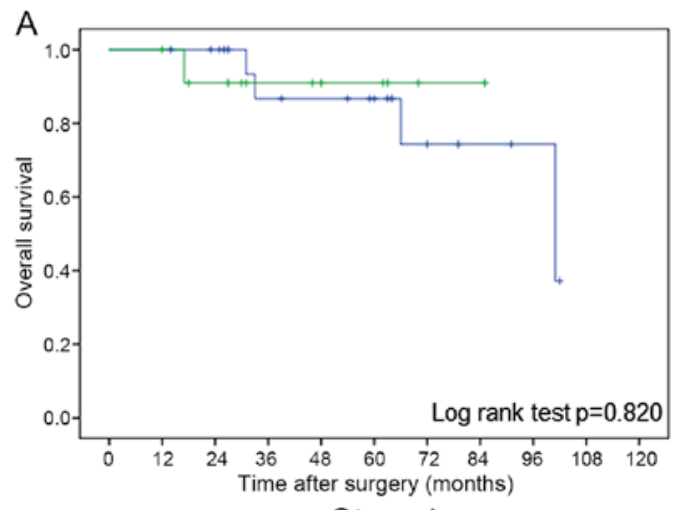

pStage I

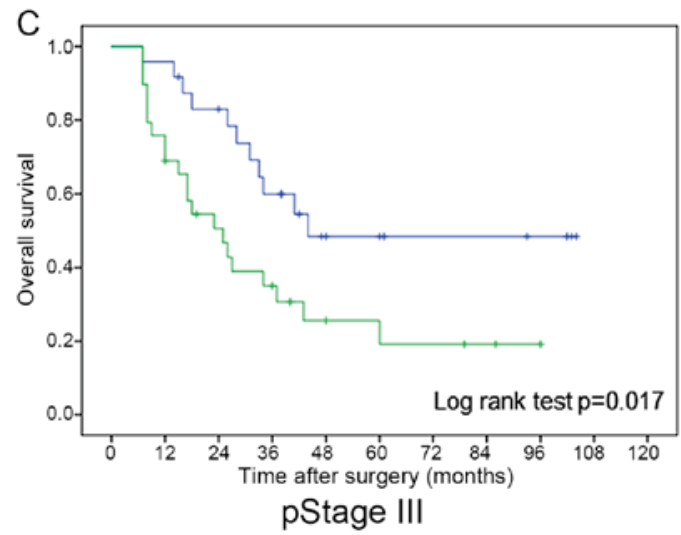

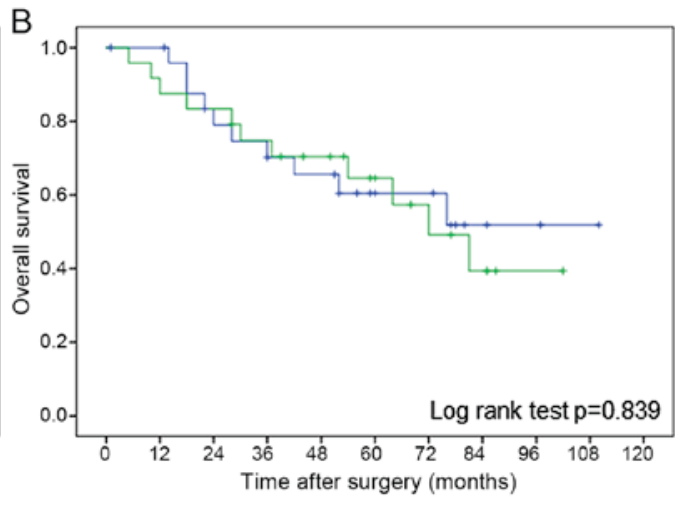

pStage II

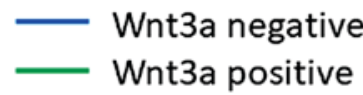

Figure 3. OS curves of each pathological stages according to Wnt3a expression. These curves were calculated by the Kaplan-Meier method. The green line is Wnt3a-positive group and the blue line is Wnt3a-negative group. Difference between two groups were evaluated by log-rank test. (A) Pathological stage I, (B) pathological stage II, (C) pathological stage III. OS, overall survival.

OS rate which were calculated by Kaplan-Meier method were poorer in Wnt3a-positive group than these in Wnt3anegative group in log-rank test $(\mathrm{P}=0.012)$ (Fig. 2). In pathological stages I and II, there was no difference in overall survival rate between Wnt3a-positive and Wnt3a-negative groups, however overall survival rate of Wnt3a-positive group was significantly worse than that of Wnt3a-negative group in pathological stage III ( $\log$ rank test; $\mathrm{P}=0.017$ ) (Fig. 3). On the other hand, there was no significant difference in DFS rate between two groups in all pathological stage. However, prognosis of Wnt3apositive group tended to be worse than that of Wnt3a-negative group in pathological stage III (log rank test; $\mathrm{P}=0.051$ ).

Next, pathological Stage III ESCC cases were focused on in order to exclude the influence of $\mathrm{T}$ factor on progression. In pathological stage III ESCC, background data of clinicophathological features in both group was shown in Table III. There was no significant different factor between two groups. Multivariate analysis by Cox proportional hazard model showed that Wnt3a expression $(\mathrm{HR}=2.531, \mathrm{P}=0.012)$ were only independent prognostic factors (Table IV).

In order to investigate the influence of Wnt3a expression on the response of chemotherapy and chemoradiotherapy after recurrence, all patients were classified into two groups, between patients with recurrence during follow-up period (recurrence group; $n=61$ ) and patients without recurrence (no recurrence group; $n=78$ ). All of patients with recurrence underwent chemotherapy or chemoradiotherapy after diagnosis of recurrence. Background data of clinicophathological features in both group was no significant different in all factors. Patients in recurrence group were classified into Wnt3a-positive $(n=35)$ and Wnt3a-negative groups $(n=26)$. In comparison with overall survival rate between two groups, Wnt3a-positive patients were significant poor prognosis than negative patients (log-rank test; $\mathrm{P}=0.023$ ) (Fig. 4). Moreover, survival after recurrence was compared with Wnt3a expression only in patients who received chemotherapy after recurrence. Twenty-eight patients with recurrence were Wnt3a-positive, and 25 patients were Wnt3a-negative. No significant difference in survival after recurrence was seen between the Wnt3a-positive and the Wnt3a-negative patients $(\mathrm{P}=0.093)$; however, the Wnt3a-positive patients tended to have a poorer survival outcome than the Wnt3a-negative patients (Fig. 5).

\section{Discussion}

In this study, it was suggested that expression of Wnt3a in cytoplasm of ESCC was a poor prognostic factor of ESCC after lymph node metastasis and venous invasion. In pathological stages I and II, there was no difference in prognosis between Wnt3a-positive and Wnt3a-negative groups, however prognosis of Wnt3a-positive group was significantly worse than that of Wnt3a-negative group in pathological stage III. Among patients with recurrence in pathological stage III, overall survival rate of Wnt3a-positive group was significant lower than that in Wnt3a-negative group.

Wnt3a is one of regular ligands of canonical Wnt signaling pathway. Several studies suggested that development and 
Table III. Comparison of clinicopathological factors between Wnt3a-positive and Wnt3a-negative groups in pathological stage III ESCC.

\begin{tabular}{|c|c|c|c|c|}
\hline Parameters & Total $(\mathrm{n}=57)$ & Wnt3a-positive $(n=32)$ & Wnt3a-negative $(n=25)$ & P-value \\
\hline Age (years; mean) & 64.3 & 66.1 & 61.9 & 0.063 \\
\hline Sex & & & & 0.520 \\
\hline Male & 45 & 24 & 21 & \\
\hline Female & 12 & 8 & 4 & \\
\hline Location of tumor & & & & 0.972 \\
\hline Upper & 5 & 3 & 2 & \\
\hline Middle & 30 & 17 & 13 & \\
\hline Lower & 22 & 12 & 10 & \\
\hline Size of tumor (mean) & 55.5 & 58.1 & 52.2 & 0.292 \\
\hline \multirow[t]{3}{*}{ Serum SCC level (ng/ml; mean) } & & & & 0.225 \\
\hline & 15 & 6 & 9 & \\
\hline & 42 & 26 & 16 & \\
\hline Differentiation & & & & 0.265 \\
\hline Well & 18 & 8 & 10 & \\
\hline Moderate & 19 & 10 & 9 & \\
\hline Poorly & 20 & 14 & 6 & \\
\hline Lymphatic invasion & & & & 1.000 \\
\hline Positive & 55 & 31 & 24 & \\
\hline Negative & 2 & 1 & 1 & \\
\hline Venous invasion & & & & 0.309 \\
\hline Positive & 53 & 31 & 22 & \\
\hline Negative & 4 & 1 & 3 & \\
\hline INF & & & & 0.589 \\
\hline $\mathrm{a}$ & 1 & 1 & 0 & \\
\hline $\mathrm{b}$ & 43 & 23 & 20 & \\
\hline $\mathrm{c}$ & 13 & 8 & 5 & \\
\hline Adjuvant chemotherapy & & & & 0.141 \\
\hline+ & 42 & 21 & 21 & \\
\hline- & 15 & 11 & 4 & \\
\hline
\end{tabular}

ESCC, esophageal squamous cell carcinoma; SCC, squamous cell carcinoma; INF, infiltrative growth pattern.

progression of glioblastoma (16), prostate cancer (12), breast cancer (17), or malignant mesothelioma (18) was related to the activity of canonical Wnt signaling pathway, and Wnt3a expression in cancer cells of colorectal cancer (19) or hepatocellular carcinoma (20) was associated with poor prognosis. There was also some study which suggested that the activity of canonical Wnt signaling pathway was related to development and prognosis of head and neck squamous cell carcinoma (21). Some study suggested that the activity of canonical Wnt signaling pathway, $\beta$-catenin and $\mathrm{TCF}-4$, which were regular factors of canonical Wnt signaling pathway, was related to prognosis of ESCC $(11,22,23)$. There was also a study which suggested that expression of dickkopf-1, which was one of inhibitor of canonical Wnt signaling pathway, was associated with poor prognosis of ESCC (15). Relationship between ESCC and canonical Wnt signaling is still controversial. Epithelialmesenchymal transition (EMT), which was proposed as one of the important mechanism of tumor growth and metastasis, was a concept of the transition from epithelial cells to mesenchymal cells. According to progression of cancer, cancer cells seems to acquire the ability of invasion and metastasis by EMT (24). Several studies already suggested that Wnt signaling pathway closely related to EMT $(25,26)$, and EMT related factors would be prognostic factors of $\operatorname{ESCC}(27,28)$. These studies support the hypothesis that the canonical Wnt signaling pathway activates the progression and metastasis of ESCC through the EMT; whether Wnt3a expression might also be correlated with the progression and metastasis of ESCC should be investigated.

In Japan, neoadjuvant chemotherapy (NAC) is a standard treatment for clinical stages II or III ESCC based on a clinical phase III trial in the country $(29,30)$. Depth of invasion, lymph node metastasis and lower level of preoperative serum albumin were poor prognostic factors for patients who performed NAC (31), therefore additional adjuvant therapy seems to be needed for them in order to improve the prognosis of high risk 
Table IV. Univariate and multivariate survival analysis of overall survival for pathological stage III ESCC patients by Cox's proportional hazard model.

\begin{tabular}{|c|c|c|c|c|c|c|}
\hline \multirow[b]{2}{*}{ Parameters } & \multicolumn{3}{|c|}{ Univariate analysis } & \multicolumn{3}{|c|}{ Multivariate analysis } \\
\hline & HR & $95 \% \mathrm{CI}$ & P-value & HR & $95 \% \mathrm{CI}$ & P-value \\
\hline \multicolumn{7}{|l|}{ Age (years) } \\
\hline$\geq 65$ vs. $\leq 64$ & 1.384 & $0.708-2.706$ & 0.342 & & & \\
\hline \multicolumn{7}{|l|}{ Sex } \\
\hline Male vs. female & 0.851 & $0.371-1.953$ & 0.703 & & & \\
\hline \multicolumn{7}{|l|}{ Location of tumor } \\
\hline Upper vs. middle and lower & 2.298 & $0.796-6.633$ & 0.124 & & & \\
\hline \multicolumn{7}{|l|}{ Size of tumor } \\
\hline$\geq 56$ vs. $\leq 55$ & 1.875 & $0.957-3.675$ & 0.067 & 1.775 & $0.894-3.524$ & 0.101 \\
\hline \multicolumn{7}{|l|}{ Serum SCC level } \\
\hline$\geq 1.5$ vs. $<1.5$ & 0.859 & $0.390-1.892$ & 0.706 & & & \\
\hline \multicolumn{7}{|l|}{ Adjuvant chemotherapy } \\
\hline Done vs. not done & 0.783 & $0.374-1.638$ & 0.515 & & & \\
\hline \multicolumn{7}{|l|}{ Differentiation } \\
\hline Poorly vs. well, moderate & 1.454 & $0.743-2.843$ & 0.274 & & & \\
\hline \multicolumn{7}{|l|}{ Infiltrative growth pattern } \\
\hline c vs. a, b & 1.003 & $0.455-2.214$ & 0.994 & & & \\
\hline \multicolumn{7}{|l|}{ Lymphatic invasion } \\
\hline Positive vs. negative & 1.052 & $0.143-7.718$ & 0.960 & & & \\
\hline \multicolumn{7}{|l|}{ Venous invasion } \\
\hline Positive vs. negative & 2.912 & $0.397-21.345$ & 0.293 & & & \\
\hline \multicolumn{7}{|l|}{ Wnt3a expression } \\
\hline Positive vs. negative & 2.719 & $1.324-5.585$ & 0.006 & 2.531 & $1.230-5.206$ & 0.012 \\
\hline
\end{tabular}

Infiltrative growth pattern: a, expansive type; b, intermediate type; and c, infiltrative type. HR, hazard ratio; ESCC, esophageal squamous cell carcinoma; CI, confidence interval; SCC, squamous cell carcinoma.

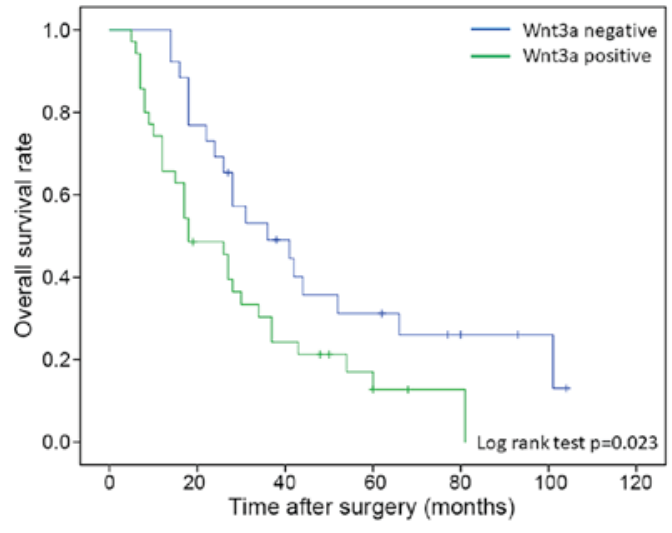

Figure 4. OS curves of patients with recurrence according to Wnt3a expression. These curves were calculated by the Kaplan-Meier method. The green line is Wnt3a-positive group and the blue line is Wnt3a-negative group. Difference between two groups were evaluated by log-rank test. OS, overall survival.

cases. However, contents of adjuvant therapy was still controversial. Our results suggested that Wnt3a is correlated with a

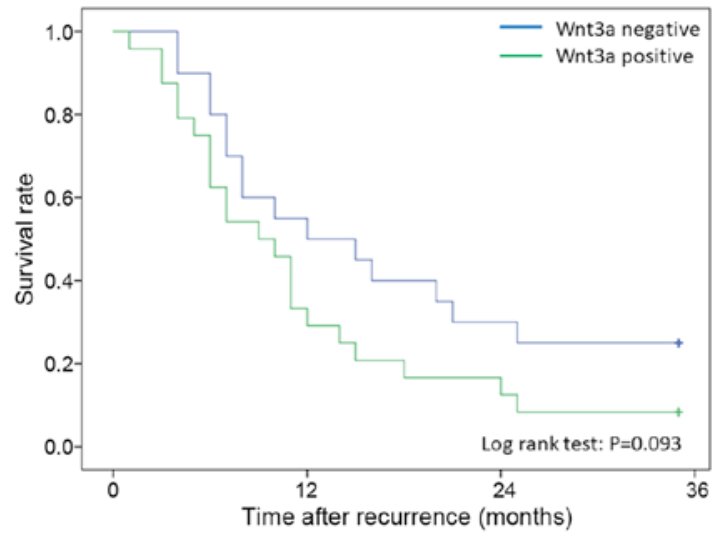

Figure 5. Survival after recurrence curve of patients according to Wnt3a expression. These curves were calculated by the Kaplan-Meier method. The green line is Wnt3a-positive group and the blue line is Wnt3a-negative group. Difference between two groups were evaluated by log-rank test.

poor prognosis in patients with stage III ESCC and that the prognosis of patients with recurrence is poorer in patients with 
Wnt3a expression than in patients without Wnt3a expression. These results suspected that patients with expression of Wnt3a may have poor response of treatment after recurrence. Although a significant correlation between survival after recurrence and Wnt3a expression was not seen, the correlation between the canonical Wnt signaling pathway, including Wnt3a, and the chemoresistance of ESCC is worth investigating. Several studies suggested that canonical Wnt signaling played a role in chemotherapy and radiation resistance of various malignancies (32-34). Advanced ESCC with positive expression of Wnt3a might have malignant potential or chemoresistance which leaded to poor prognosis and Wnt3a also may be a target of adjuvant therapy for high risk cases who performed NAC.

Expression of Wnt3a in ESCC was more associated with the depth of invasion and histological differentiation of main tumor than with lymph node metastasis and vessel invasion. Some studies suggested that Wnt3a expression was also related to histological differentiation of colon cancer (19) and hepatocellular carcinoma (20). These results suggested that upper stream factor of canonical Wnt signaling pathway, such as Wnt3a, seemed to be more associated with local development and differentiation of tumor than with migration and metastasis, and then it would be identified as a poor prognostic factor of ESCC.

The limitations of this study were that it was a retrospective study and the small number of patients who were enrolled in present study, and it was investigated about Wnt3a alone which was one of factors related to canonical Wnt signaling pathway. Generally, cell signaling pathway was activated by the interaction of a lot of factors. Therefore, the role of $\mathrm{Wnt} 3 \mathrm{a}$ in the progression of ESCC was not clear in this study. In order to investigate the mechanism of ESCC progression, a lot of factors, investigation in the cell cultures and animal models will be needed in the future.

To our knowledge, this study was a first study which suggested that Wnt3a seemed to be a prognostic factor of ESCC. It is expected that relationship between ESCC and canonical Wnt signaling pathway will be clear based on this study and development of novel treatment for ESCC with poor prognosis will progress in the future.

\section{References}

1. Tachimori Y, Ozawa S, Numasaki H, Fujishiro M, Matsubara H, Oyama T, Shinoda M, Toh Y, Udagawa H, Uno T, et al: Comprehensive regitry of esophageal cancer in Japan, 2009. Esophagus 13: 110-137, 2016.

2. Kikuchi A, Yamamoto $\mathrm{H}$ and Sato A: Selective activation mechanisms of Wnt signaling pathways. Trends Cell Biol 19: 119-129, 2009.

3. Duchartre Y, Kim YM and Kahn M: The Wnt signaling pathway in cancer. Crit Rev Oncol Hematol 99: 141-149, 2016.

4. Behrens J, von Kries JP, Kühl M, Brihn L, Wedlich D, Grosschedl R and Birchmeier W: Functional interaction of beta-catenin with the transcription factor LEF-1. Nature 382 638-642, 1996.

5. Molenaar M, van de Wetering $M$, Oosterwegel $M$, Peterson-Maduro J, Godsave S, Korinek V, Roose J, Destrée $\mathrm{O}$ and Clevers H: XTcf-3 transcription factor mediates beta-catenin-induced axis formation in Xenopus embryos. Cell 86: 391-399, 1996

6. Nelson WJ and Nusse R: Convergence of Wnt, beta-catenin, and cadherin pathways. Science 303: 1483-1487, 2004.

7. Firestein R, Bass AJ, Kim SY, Dunn IF, Silver SJ, Guney I, Freed E, Ligon AH, Vena N, Ogino S, et al: CDK8 is a colorectal cancer oncogene that regulates beta-catenin activity. Nature 455 : $547-551,2008$
8. Fritzmann J, Morkel M, Besser D, Budczies J, Kosel F, Brembeck FH, Stein U, Fichtner I, Schlaq PM and Birchmeier W: A colorectal cancer expression profile that includes transforming growth factor beta inhibitor BAMBI predicts metastatic potential. Gastroenterology 137: 165-175, 2009.

9. Takigawa $\mathrm{Y}$ and Brown AM: Wnt signaling in liver cancer. Curr Drug Targets 9: 1013-1024, 2008.

10. Zhang S, Li J, He F and Wang XM: Abnormal nuclear expression of Pygopus-2 in human primary hepatocellular carcinoma correlates with a poor prognosis. Histopathology 67: 176-184, 2015.

11. Fu L, Zhang C, Zhang LY, Dong SS, Lu LH, Chen J, Dai Y, Li Y, Kong KL, Kwong DL and Guan XY: Wnt2 secreted by tumour fibroblasts promotes tumour progression in oesophageal cancer by activating of the Wnt/ $\beta$-catenin signaling pathway. Gut 60 : 1635-1643, 2011.

12. Verras M, Brown J, Li X, Nusse R and Sun Z: Wnt3a growth factor induces androgen receptor-mediated transcription and enhances cell growth in human prostate cancer cells. Cancer Res 64: 8860-8866, 2004.

13. Gao Q, Qin SJ, Fan J, Zhou J, Xiao YS, Xu Y, Li YW and Tang ZY: Intratumoral balance of regulatory and cytotoxic $\mathrm{T}$ cells is associated with prognosis of hepatocellular carcinoma after resection. J Clin Oncol 25: 2586-2593, 2007.

14. Bisson I and Prowse DM: WNT signaling regulates self-renewal and differentiation of prostate cancer cells with stem cell characteristics. Cell Res 19: 683-697, 2009.

15. Makino T, Yamasaki M, Takemasa I, Takeno A, Nakamura Y, Miyata H, Takiguchi S, Fujiwara Y, Matsuura N, Mori M and Doki Y: Dickkopf-1 expression as a marker for predicting clinical outcome in esophageal squamous cell carcinoma. Ann Surg Oncol 16: 2058-2064, 2009.

16. Kaur N, Chettiar S, Rathod S, Rath P, Muzumdar D, Shaikh ML and Shiras A: Wnt3a mediated activation of Wnt $/ \beta$-catenin signaling promotes tumor progression in glioblastoma. Mol Cell Neurosci 54: 44-57, 2013.

17. King TD, Suto MJ and Li Y: The Wnt/ $\beta$-catenin signaling pathway: A potential therapeutic target in the treatment of triple negative breast cancer. J Cell Biochem 113: 13-18, 2012.

18. Fox SA, Richards AK, Kusumah I, Perumal V, Bolitho EM, Mutsaers SE and Dharmarajan AM: Expression profile and function of Wnt signaling mechanisms in malignant mesothelioma cells. Biochem Biophys Res Commun 440: 82-87, 2013.

19. Qi L, Sun B, Liu Z, Cheng R, Li Y and Zhao X: Wnt3a expression is associated with epithelial-mesenchymal transition and promotes colon cancer progression. J Exp Clin Cancer Res 33: 107, 2014

20. Pan LH, Yao M, Cai Y, Gu JJ, Yang XL, Wang L and Yao DF: Oncogenic Wnt3a expression as an estimable prognostic marker for hepatocellular carcinoma. World J Gastroenterol 22: 3829-3836, 2016

21. Goto M, Mitra RS, Liu M, Lee J, Henson BS, Carey T, Bradford C, Prince M, Wang CY, Fearon ER and D'Silva NJ: Rap1 stabilizes beta-catenin and enhances beta-catenin-dependent transcription and invasion in squamous cell carcinoma of the head and neck. Clin Cancer Res 16: 65-76, 2010.

22. Deng F, Zhou K, Cui W, Liu D and Ma Y: Clinicopathological significance of $w n t / \beta$-catenin signaling pathway in esophageal squamous cell carcinoma. Int J Clin Exp Pathol 8: 3045-3053, 2015.

23. Ishiguro H, Wakasugi T, Terashita Y, Sakamoto N, Tanaka T, Sagawa H, Okubo T and Takeyama H: Nuclear expression of TCF4/TCF7L2 is correlated with poor prognosis in patients with esophageal squamous cell carcinoma. Cell Mol Biol Lett 21: 5, 2016.

24. Thiery JP: Epithelial-mesenchymal transitions in tumor progression. Nat Rev Cancer 2: 442-454, 2002.

25. Thiery JP, Acloque H, Huang RY and Nieto MA: Epithelial-mesenchymal transitions in development and disease. Cell 139: 871-890, 2009.

26. Smith BN and Bhowmick NA: Role of EMT in metastasis and therapy resistance. J Clin Med 5: E17, 2016.

27. Tanaka M, Kijima H, Shimada H, Makuuchi H, Ozawa S and Inokuchi S: Expression of podoplanin and vimentin is correlated with prognosis in esophageal squamous cell carcinoma. Mol Med Rep 12: 4029-4036, 2015.

28. Jin H, Morohashi S, Sato F, Kudo Y, Akasaka H, Tsutsumi S, Ogasawara H, Miyamoto K, Wajima N, Kawasaki H, et al: Vimentin expression of esophageal squamous cell carcinoma and its aggressive potential for lymph node metastasis. Biomed Res 31: 105-112, 2010. 
29. Ando N, Iizuka T, Ide H, Ishida K, Shinoda M, Nishimaki T, Takiyama W, Watanabe H, Isono K, Aoyama N, et al: Surgery plus chemotherapy compared with surgery alone for localized squamous cell carcinoma of the thoracic esophagus: A Japan Clinical Oncology Group Study-JCOG9204. J Clin Oncol 21: 4592-4596, 2003.

30. Ando N, Kato H, Igaki H, Shinoda M, Ozawa S, Shimizu H, Nakamura T, Yabusaki H, Aoyama N, Kurita A, et al: A randomized trial comparing postoperative adjuvant chemotherapy with cisplatin and 5-fluorouracil versus preoperative chemotherapy for localized advanced squamous cell carcinoma of the thoracic esophagus (JCOG9907). Ann Surg Oncol 19: 68-74, 2012.

31. Yokota T, Ando N, Igaki H, Shinoda M, Kato K, MIzusawa J, Katayama H, Nakamura K, Fukuda H and Kitagawa Y: Prognostic factors in patients receiving neoadjuvant 5-fluorouracil plus cisplatin for advanced esophageal cancer (JCOG9907). Oncology 89: 143-151, 2015.
32. Jamieson $\mathrm{CH}$, Ailles LE, Dylla SJ, Muijtjens M, Jones C, Zehnder JL, Gotlib J, Li K, Manz MG, Keating A, et al: Granulocyte-macrophage progenitors as candidate leukemic stem cells in blast-crisis CML. N Engl J Med 351: 657-667, 2004.

33. Yang W, Yan HX, Chen L, Liu Q, He YQ, Yu LX, Zhang SH, Huang DD, Tang L, Kong XN, et al: Wnt/beta-catenin signaling contributes to activation of normal and tumorigenic liver progenitor cells. Cancer Res 68: 4287-4295, 2008

34. Noda T, Nagano H, Takemasa I, Yoshioka S, Murakami M, Wada H, Kobayashi S, Marubashi S, Takeda Y, Dono K, et al: Activation of Wnt/beta-catenin signaling pathway induces chemoresistance to interferon-alpha/5-fluorouracil combination therapy for hepatocellular carcinoma. Bri J Cancer 100: 1647-1658, 2009. 